\title{
LA-MC-ICP-MS Sr isotope analysis of speleothems - choosing the right reference material
}

\author{
Michael Weber ${ }^{1}$, Denis Scholz $Z^{1}$, Regina MertZ- \\ KRAUS $^{1}$, KLAUS PETER JOCHUM ${ }^{2}$ \\ ${ }^{1}$ Institute for Geosciences, Johannes Gutenberg University, \\ Mainz, Germany \\ ${ }^{2}$ Max-Planck-Institute for Chemistry, Mainz, Germany
}

Speleothems are well established palaeoclimate archives and offer a variety of different geochemical proxies. Besides traditional proxies, such as trace elements and $\delta^{13} \mathrm{C}$ and $\delta^{18} \mathrm{O}$ values, $\mathrm{Sr}$ isotope ratios $\left({ }^{87} \mathrm{Sr} /{ }^{86} \mathrm{Sr}\right)$ can provide valuable information about water residence time and the source of the $\mathrm{Sr}$ incorporated in a speleothem [1,2].

Due to the fast nature of laser ablation analysis, the coupling with a MC-ICP-MS instrument allows a large throughput of samples, fast data acquisition as well as a high spatial resolution without the need of chemical purification. However, to obtain reliable results, not only the successful correction of potentially interfering elements (i.e., $\mathrm{Rb}$ and REEs), but also the careful monitoring of suitable reference materials is crucial for in-situ analyses of $\mathrm{Sr}$ isotopes by LAMC-ICP-MS. Preferentially, a reference material with a similar $\mathrm{Sr}$ mass fraction should be chosen to monitor the accuracy of the unknown ${ }^{87} \mathrm{Sr} /{ }^{86} \mathrm{Sr}$ ratio of the samples.

Speleothems usually consist of calcite and reveal rather small mass fractions of $\mathrm{Sr}$ in the range of $500 \mu \mathrm{g} / \mathrm{g}$ and below. However, most of the available carbonate reference materials (e.g.,GSJ JCt-1, JCp-1 and USGS MACS-3) have much higher $\mathrm{Sr}$ mass fractions $(>1400 \mu \mathrm{g} / \mathrm{g})$. This shows the need of suitable carbonate reference materials for samples with smaller $\mathrm{Sr}$ mass fractions. The recently published NanoSr, a synthethic carbonate nanopowder, is a reference material with a $\mathrm{Sr}$ mass fraction of ca. $500 \mu \mathrm{g} / \mathrm{g}$, which is much closer to those of speleothem samples [3].

Here we present $\mathrm{Sr}$ isotope data from various speleothem samples, covering different time spans and climate regimes. Due to the small $\mathrm{Sr}$ mass fraction of most samples, we used NanoSr to monitor the accuracy of the speleothem ${ }^{87} \mathrm{Sr} /{ }^{86} \mathrm{Sr}$ data. These results are compared with data from speleothem samples consisting of aragonite and thus providing a larger $\mathrm{Sr}$ mass fraction. This allows the comparison with data obained using reference materials with larger mass fractions.

[1] McDermott (2004) QSR 23, 901-918. [2] Banner et al. (1996) Geology 22, 687-690. [3] Weber et al. (2019) GGR. 